\title{
DOIS CONCEITOS DE ATIVISMO JUDICIAL E ANÁLISE DA ADI 4.277
}

\author{
Gabriel Santos Rios ${ }^{1}$ e Carlos Eduardo Behrmann Rátis Martins ${ }^{2}$ \\ 1. Estagiário PEVIC/UEFS, Graduando em Direito, Universidade Estadual de Feira de Santana, e-mail: \\ gabrielsrios@outlook.com \\ 2. Orientador, Departamento de Ciências Sociais Aplicadas, Universidade Estadual de Feira de Santana, e-mail: \\ carlosratis@uol.com.br
}

PALAVRAS-CHAVE: ativismo judicial; uniões homoafetivas; jurisdição constitucional.

\section{INTRODUÇÃO}

O constitucionalismo contemporâneo tem como uma de suas principais características a expansão da jurisdição constitucional, como instância de controle da força normativa da Lei Maior. O Brasil não escapa a essa tendência: a Constituição Federal de 1988, no caput do artigo 102, atribui expressamente ao Supremo Tribunal Federal o poder-dever de guardá-la.

Essa competência inclui, entre outras atribuições, a de fiscalizar a conformidade dos atos do Poder Legislativo com a Constituição, o que, por vezes, provoca tensões entre a atividade política dos representantes democraticamente eleitos e a conservação da posição hierarquicamente privilegiada da Constituição no ordenamento jurídico pátrio.

No caso de rompimento do equilíbrio entre a atuação do legislador e o controle de constitucionalidade exercido judicialmente, corre-se o risco de concentrar de modo ilegítimo, em um só órgão, um feixe de funções estatais que a Constituição, sob a influência das teorias da separação dos poderes (MONTESQUIEU, 2000), distribuiu.

A possibilidade de sobreposição de Poderes é agravada quando se toma em consideração a opção do Constituinte de utilizar, na maioria das vezes, disposições normativas vagas e/ou ambíguas, aumentando, portanto, o espaço de conformação e criação do intérprete.

Nesse contexto, debate-se a atuação do STF em casos de alta repercussão social, como a ADI 4.277 (BRASIL, 2011), objeto da presente investigação, que, por unanimidade, decidiu pela possibilidade da inserção da união homossexual no instituto jurídico da união estável, inobstante a falta de previsão legislativa nesse sentido.

Entre a terminologia utilizada tanto por detratores quanto por apoiadores de decisões dessa natureza, a expressão "ativismo judicial" parece ser uma constante nas análises, mas com denotações e conotações as mais diversas, como Dimitri Dimoulis e Soraya Lunardi (2011) reconhecem.

Assumindo, com Inocêncio Coelho (2010, p. 110), que "a gramática do tema é a higiene da controvérsia", faz-se necessário reduzir as indeterminações semânticas que gravitam em torno do conceito de ativismo judicial, o que justifica a bipartição da pesquisa em um momento conceitual, onde revisar-se-á a principal bibliografia nacional que trata do tema e um momento de estudo do caso-objeto.

Pretende-se, portanto, analisar o acórdão da ADI 4.277 à luz do conceito de ativismo judicial, a fim de perquirir sobre o respeito aos limites das competências constitucionalmente delimitadas na intervenção do Supremo Tribunal Federal, isto é, se o STF pode suprir a omissão legislativa em reconhecer juridicamente as uniões homoafetivas enquanto uniões estáveis.

A relevância do trabalho consiste na promoção do controle social das instituições e da fiscalização da força normativa da Lei Maior, submetendo a decisão, cujos desdobramentos provocam intensos debates públicos, ao crivo de uma análise de racionalidade, consistência e coerência jurídicas dos fundamentos argumentativos utilizados pelos Ministros, permitindo, também, uma reflexão crítica sobre o conceito de ativismo judicial e o papel dos tribunais em uma democracia constitucional. 


\section{MATERIAL E MÉTODOS OU METODOLOGIA (ou equivalente)}

Trata-se de uma pesquisa que transita entre a Teoria do Direito e a Teoria da Constituição, amparada na investigação de conceitos (a exemplo de "ativismo judicial"), o que torna a pesquisa bibliográfica o método mais adequado para alcançar seus objetivos, mediante uma revisão de literatura centrada nas obras de Elival da Silva Ramos (2015), Dimitri Dimoulis e Soraya Lunardi (2011) e Luís Roberto Barroso (2011, 2015), não obstante a dimensão empírica de análise da atuação do Supremo Tribunal Federal na ADI 4.277.

\section{RESULTADOS E/OU DISCUSSÃO (ou Análise e discussão dos resultados)}

A categoria de inteligibilidade "ativismo judicial" é alvo de intensas discussões tanto em relação ao seu conteúdo valorativo (se é um fenômeno positivo ou negativo) quanto no que tange à sua caracterização (se, em face de um determinado pronunciamento judicial, estáse ou não diante de uma atuação ativista).

A própria utilidade do conceito chegou a ser questionada, já que a sua baixa densidade semântica impediria que contribuísse para uma discussão séria acerca dos limites da atividade jurisdicional, sendo apenas um clichê constitucional "destinado à simplificação excessiva das questões a ela [a expressão] relacionadas" (PÁDUA, 2015, p. 163).

A proposta de abandono do conceito não é justificável: a sua incorporação à gramática das discussões constitucionais e a possibilidade (sustentada a seguir) de propor parâmetros para delimitá-lo são boas razões para continuar a utilizá-lo mesmo em vista da vagueza e da ambiguidade que o cercam.

Há, igualmente, os que propõem um critério quantitativo para caracterizar o ativismo judicial, como Thamy Pogrebinschi (2012, p. 183), que questiona a imputação da qualificação de "ativista" para o Supremo Tribunal Federal com dados empíricos que, segundo a autora, revelam que "o Supremo é, na verdade, muito mais deferente ao Congresso do que a ausência de pesquisa empírica pode fazer supor".

Essa concepção desconsidera, entretanto, a distinção entre judicialização e ativismo judicial (BARROSO, 2011): a judicialização consiste na submissão de questões controversas à apreciação do Poder Judiciário, sendo a expressão costumeiramente utilizada para tratar de matérias que, tradicionalmente, não eram objeto de exame judicial aprofundado.

A mera judicialização foge ao controle do Poder Judiciário e, por essa razão, não pode ser vista como indício seguro de atuação ativista. $\mathrm{O}$ ativismo judicial é uma reação do Poder Judiciário ao fenômeno da judicialização, no sentido de apreciar questões que, de acordo com uma dada concepção acerca da divisão das funções estatais, estariam, prima facie, no âmbito de competência de um outro Poder.

Não se pode negar, desse modo, a qualificação de "ativista" a um determinado tribunal por prestar deferência a outro Poder em um sem-número de casos, mas não o fazer (quando deveria) em uma outra porção, ainda que reduzida, das questões judicializadas.

Por outro lado, Dimitri Dimoulis e Soraya Gasparetto Lunardi (2011, p. 462) observam que não se pode qualificar de ativista a atividade intensa de um tribunal no combate à "atuação sistemática do legislador em desrespeito à Constituição", assim como seria descabido "chamar de 'ativista' um médico que atende muitos pacientes durante uma epidemia".

Pode-se dizer, nessa linha, que a nota central do conceito de ativismo judicial é "o exercício da função jurisdicional para além dos limites impostos pelo próprio ordenamento que incumbe ao Poder Judiciário fazer atuar" (RAMOS, 2015, p. 131).

Contudo, contrariamente ao que sustenta Elival da Silva Ramos (2015), essa ideia não é suficiente para caracterizar uma atuação ativista. É necessário complementá-la, inicialmente, com um elemento finalístico: o ativismo judicial não é o mero transbordamento da função que 
incumbe ao Poder Judiciário, mas uma atuação expansiva com o intuito de obter determinados resultados políticos (em sentido amplo) tidos como favoráveis.

Essa observação é necessária para distinguir a atuação de um juiz ativista daquela de um magistrado prevaricador que "vende" uma sentença ou alarga as suas atribuições para prejudicar um desafeto, o que não corresponde ao uso corrente da expressão nem seria útil para a discussão constitucional.

É imprescindível, do mesmo modo, distinguir dois sentidos do conceito de ativismo judicial, conforme o parâmetro adotado para caracterizar a função jurisdicional: um sentido amplo, que não se prende às atribuições do Poder Judiciário em um determinado tempo ou lugar, e um sentido estrito, mediante o qual a argumentação se desenvolve nos marcos de um determinado ordenamento jurídico.

Esclarecido o conceito de ativismo judicial, parte-se à análise do acórdão proferido na ADI 4.277 (BRASIL, 2011), que tem por objeto a constitucionalidade do art. 1.723 do Código Civil, que, supostamente, veda o reconhecimento jurídico de uniões estáveis homoafetivas, ao prever que "é reconhecida como entidade familiar a união estável entre o homem e a mulher".

Nessa ocasião, o STF (BRASIL, 2011) decidiu reconhecer a juridicidade das uniões estáveis homoafetivas, conferindo à disposição legislativa mencionada "interpretação conforme à Constituição", com base nas seguintes razões: (i) a Constituição pró́be a discriminação das pessoas em razão do sexo e do gênero; (ii) a Constituição prevê o pluralismo como valor fundante da estrutura social pátria; (iii) há de se respeitar a liberdade e a autonomia privada para dispor da própria sexualidade; (iv) o silêncio constitucional em reconhecer expressamente as uniões homoafetivas deve ser interpretado como permissão, com base na dignidade da pessoa humana; e (v) o caput do artigo 226 da Constituição constitui uma cláusula geral de abertura às diversas formas de constituir uma família.

Essa decisão foi alvo de inúmeras críticas doutrinárias, como as de Leonardo Martins (2014) e Lenio Streck (2014), que argumentam que: (i) a Constituição prevê expressamente o reconhecimento da união estável entre homem e mulher para efeito de proteção do Estado (art. 226, § $3^{\circ}$ ); (ii) não se pode utilizar a técnica de interpretação conforme à Constituição contra expresso dispositivo constitucional; e (iii) o STF deve respeitar as decisões tomadas pelo legislador em seu espaço de conformação constitucionalmente legitimado.

Virgílio Afonso da Silva (2014) aponta, ainda, que, embora o reconhecimento das uniões homoafetivas por decisões de cortes constitucionais seja uma tendência internacional, o Brasil foi o único país em que não houve sequer tentativa de diálogo institucional com o legislador (representado, no caso em questão, pelo Congresso Nacional).

Por todos esses conflitos acerca de como deveria agir o STF perante a questão judicializada, pode-se ver que se trata de controvérsia que lida com os limites da função jurisdicional, estando, portanto, relacionada ao conceito de ativismo judicial proposto anteriormente.

Reconhece-se que a decisão é inconsistente em diversos aspectos formais e metodológicos, conforme as críticas já mencionadas: é inviável realizar interpretação conforme à Constituição de um dispositivo que se limita a praticamente reproduzi-la.

A decisão constitucional, por outro lado, é clara no sentido de reconhecer "a união estável entre o homem e a mulher como entidade familiar" (art. 226, $\S 3^{\circ}$ ), o que, a não ser que se admita a perigosa tese das normas constitucionais inconstitucionais, implica a impossibilidade de superá-la por decisão judicial.

Contudo, simultaneamente, reconhece-se que, sob o aspecto substancial, não há motivos razoáveis para impedir o reconhecimento das uniões estáveis homoafetivas, restando em aberto a questão de se a finalidade pretendida nesse caso justifica o exercício do ativismo judicial em sua acepção estrita. 


\section{REFERÊNCIAS}

BARROSO, Luís Roberto. Judicialização, Ativismo e Legitimidade Democrática. In: COUTINHO, Jacinto de Miranda (org.) et al. Constituição e Ativismo Judicial - Limites e Possibilidades da Norma Constitucional e da Decisão Judicial. Rio de Janeiro: Lumen Juris, 2011, p. 275-290.

BARROSO, Luís Roberto. A razão sem voto: o Supremo Tribunal Federal e o governo da maioria. Revista Brasileira de Políticas Públicas, Brasília, v. 5, n. especial, p. 24-51, 2015.

BRASIL. Supremo Tribunal Federal. Ação Direta de Inconstitucionalidade $n^{\circ} 4.277$. Relator: Ministro Carlos Ayres Britto. Brasília (DF), 05 de maio de 2011. Disponível em: $<$ http://redir.stf.jus.br/paginadorpub/paginador.jsp?docTP=AC\&docID=628635>. Acesso em: $12 / 10 / 2017$.

COELHO, Inocêncio Mártires. Da Hermenêutica Filosófica à Hermenêutica Jurídica: fragmentos. São Paulo: Saraiva, 2010.

DIMOULIS, Dimitri; LUNARDI, Soraya. Ativismo e autocontenção judicial no controle de constitucionalidade. In: NOVELINO, Marcelo (org.) et al. As Novas Faces do Ativismo Judicial. Salvador: JusPodivm, 2011, p. 459-473.

MARTINS, Leonardo. Reconhecimento da união estável homoafetiva como direito fundamental pela justiça constitucional. Revista de Direito da Universidade de Brasília, Brasília, v. 1, n. 1, p. 245-279, jan./jun. 2014.

MONTESQUIEU, Charles. Do Espírito das Leis. 2. ed. São Paulo: Martins Fontes, 2000.

PÁDUA, Thiago Aguiar. A expressão "ativismo judicial", como um "cliché constitucional", deve ser abandonada: uma análise crítica. Revista Brasileira de Políticas Públicas, Brasília, v. 5, n. especial, p. 136-169, 2015.

POGREBINSCHI, Thamy. Judicialização ou representação? Política, direito e democracia no Brasil. Rio de Janeiro: Elsevier, Konrad Adenauer e Ed. Campus, 2012.

RAMOS, Elival da Silva. Ativismo Judicial: Parâmetros Dogmáticos. 2. ed. Saraiva: São Paulo, 2015.

SILVA, Virgílio Afonso da. La unión entre personas del mismo género: cuán importantes son los textos y las instituciones? Revista Discusiones, Buenos Aires, v. 2, n. 15, p. 171-203, 2014.

STRECK, Lenio. O caso da ADPF 132: defender o texto da Constituição é uma atitude positivista (ou originalista)? Revista de Direito da Universidade de Brasília, Brasília, v. 1, n. 1, p. 280-304, jan./jun. 2014. 